\section{Roche's reply}

The debate continues on the Séveso disaster. Alastair Hay reports

In an effort to counter the criticism of of its subsidiary Givaudan, the Swiss multinational pharmaceutical company Hoffman-La Roche has recently given wide publicity to an internal newsletter on the environmental hazards at the Italian town of Séveso. The town was contaminated on 10 July last year by an explosive discharge from a chemical reactor manufacturering trichlorophenol. The discharge contained an extremely toxic contaminant, dioxin.

Over the past few months many press, radio and television reports have referred to the deteriorating position at Séveso. These reports quite naturally directed attention to Givaudan, the owners of the Icmesa chemical plant responsible for the contamination problem, and have been extremely critical of the company. The Roche newsletter represents an attempt on the behalf of its subsidiary to redress the balance. It claims to produce as objective an account as possible of the picture at Séveso, speaking of "considerable progress" made in the diecontamination effort and the settlement of private compensation claims, and it refers to the "encouraging" health situation.

But the newsletter is primarily concerned with the prevailing position, referring only in passing to the circumstances of the actual 10 July accident. The reactor's explosive discharge is referred to as a toxic mixture of chemicals which escaped from the plant "as a result of a runaway reaction". As the cause of the accident is the subject of a legal inquiry by an Italian court, Givaudan obviously prefers not to make public pronouncements about the case.

In private, however, a company spokesman maintains that even after months of tests they still do not know what caused the accident. Givaudan can hardly deny that its Icmesa plant was the cause of the problem, but the company denies vehemently the suggestion that it was in any way negligent. "Human error" is mooted as the probable cause of the explosion.

Company officials insist that Givaudan knew of the previous accidents in trichlorophenol plants-at least nine have been publicly documented since 1949, and it is thought there may have been as many as 14 . The officials say Givaudan accordingly designed the plant to incorporate safety features to protect employees. This meant that the safety valve and vent pipe were placed to discharge the neactor contents away from the confines of the factory-with the disastrous consequences that the July accident demonstrated. The company now admits that there may have been a "lack of foresight" in anticipating this event.

In response to accusations that the company withheld information on its reaction processes, Givaudan insists that it had all the necessary permits authorising operations on the site. As for the trichlorophenol reaction, dioxin production was constantly monitored and ranged from $10-30$ $\mathrm{ppb}$, well below the level recorded in other plants producing trichlorophenol destined for the manufacture of the herbicide 2,4,5-T.

The company maintains that two weeks was necessary to assess the extent of the contamination in the Icmesa neighbourhood after the accident, but that as soon as reliable data was to hand, it was passed to the Italian authorities.

One of the principal problems facing the Italian authorities and Roche was the paucity of clinical information on dioxin toxicity in humans. Dr Giuseppe Reggiani, director of clinical research for Roche, says the health situation at Séveso is "reassuring". He insists, however, that certain categories of high risk groups, in particular the children with chloracne and the residents of the heavily contaminated Zone $A$, be constantly monitored as part of an epidemiological survey.

The Lombardy regional authority is to undertake such a survey under the auspices of its Health and Epidemiology Commission. The commission proposes to measure some 22 biochemical parameters in a population they consider likely to have been in contact with dioxin. The authority expects Givaudan to pay for the operation. The company, on the other hand, insists that before government claims can be met, due weight will have to be accorded to one of their decontamination proposals, made in August of last year. This proposal was not accepted by the Italian authorities, but would have involved the spraying of vegetation with an olive oilcyclohexanone mixture, which would have facilitated the photoreduction of dioxin present. Givaudan claims that its programme could have resulted in the destruction of $80-90 \%$ of the dioxin.
BRITAIN

\section{Down wind}

WiTH the publication last week of a 70-page report on wind energy*, the UK Department of Energy (DEN) has now completed its first round of studies on alternative energy sources. Responding to a question at a press conference last week to introduce the report, the department's chief scientist, Dr Walter Marshall, said it was "unambiguously clear" that the source which was "top of the pops" was wave power. That was followed by solar power, then geothermal and tidal power.

Final judgment, according to the head of the DEN's Energy Technology Support Unit at Harwell, Dr K. Dawson, would depend on economic and environmental considerations as well as potential contributions to total energy needs. But it was clear, he said, that wind woudn't solve the country's energy problems. Marshall himself accorded it low priority because, he said, he has doubts whether it will be environmentally satisfactory.

That small dampener does not mean the DEN is not going to pursue the matter. The department and an industrial consortium are each pitching $£ 75,000$ into what is called a "detailed design study for a large machine installed on a prime site"; another $£ 10,000$ is coming from two interested Scottish utilities. The idea is to obtain a firmer estimate of costs, to improve the confidence with which the current cautiously optimistic estimates are held.

But, as Marshall sees it, there is a problem. If it is environmentally acceptable to use the 3.000-odd identified sites and it is possible to put aerogenerators on them, the costs might be reasonable and wind energy might seem economic even now at current prices. But, he goes on, if there is less confidence about the sites and it is left to the market to introduce wind power, the number of sites used would be small, costs would be high and wind power would hardly be economic.

Last week's report was completed before Sir Martin Ryle, the Astronomer Royal, detailed his arguments favouring wind power in an article in Nature on the economics of alternative energy sources. Asked whether Ryle's arguments would be incorporated into DEN work. Marshall said that, now the DEN had finished its own calculations, he was trying to get people together, including Ryle, to see what should be done next.

Marshall's personal view, that economic debate lies somewhere between resolvable disagreement on technological fact and irresolvable disagreement on religious theology, leads him to look for agreement on what should be done to resolve uncertainties. Hence his own preference, amply demonstrated in the case of wind power, for a systematic step-by-step scaling-up approach - view which, as he points out, also goes down well with the Treasury.

Chris Sherwell

*The prospects for the generation of electricity from wind energy in the United Kingdom. Energy Paper Number 21 (HMSO, £2.25). 